\title{
L-OPERATOR INTEGRO-DIFFERENTIAL INEQUALITY FOR DISSIPATIVITY OF STOCHASTIC INTEGRO-DIFFERENTIAL EQUATIONS
}

\author{
LIGUANG XU AND FAJIN QIN
}

\begin{abstract}
In this paper, Itô stochastic integro-differential equations are considered. By establishing an $L$-operator integro-differential inequality and using the properties of $M$-cone and stochastic analysis technique, we obtain some new sufficient conditions ensuring the exponential $p$-dissipativity of the stochastic integro-differential equations. An example is also discussed to illustrate the efficiency of the obtained results.
\end{abstract}

Mathematics subject classification (2010): 60H20, 34K50.

Keywords and phrases: Stochastic; $P$-dissipativity; Integro-differential; $L$-operator; integro-differential inequality.

\section{REFERENCES}

[1] K. Gopalsamy, Stability and Oscillations in Delay Differential Equations of Population Dynamics, Kluwer Academic Publishers, Dordrecht, 1992.

[2] J. K. HaLE, Theory of Functional Differential Equations, Springer, New York, 1977.

[3] V. B. Kolmanovskit, A. Myshkis, Applied Theory of Functional Differential Equations, Kluwer Academic Publishers, Dordrecht, 1992.

[4] D. Y. XU, Integro-differential equations and delay integral inequalities, Tohoku Math. J., 44 (1992), 365-378.

[5] H. Y. ZHAO, Invariant set and attractor of nonautonomous functional differential systems, J. Math. Anal. Appl., 282 (2003), 437-443.

[6] D. Y. XU, H. Y. ZHAO, Invariant set and attractivity of nonlinear differential equations with delays, Appl. Math. Lett., 15 (2002), 321-325.

[7] Y. M. HuAnG, D. Y. XU, Z. C. YANG, Dissipativity and periodic attractor for non-autonomous neural networks with time-varying delays, Neurocomputing, 70 (2007), 2953-2958.

[8] L. S. WANG, D. Y. XU, Aaymptotic behavior of a class of reaction-diffusion equations with delays, J. Math. Anal. Appl., 281 (2003), 439-453.

[9] Y. J. WANG, D. S. LI, P. E. KLOEDEN, On the asymptotical behavior of nonautonomous dynamical systems, Nonliear Anal., 59 (2004), 35-53.

[10] X. X. LiAO, J. WANG, Global dissipativity of continuous-time recurrent neutral networks with time delay, Phys. Rev. E, 68 (2003), 1-7.

[11] I.-G. E. Kordonis, CH. G. PhILOS, The behavior of solutions of linear integro-differential equations with unbounded delay, Comput. Math. Appl., 38 (1999), 45-50.

[12] X. Y. LoU, B. T. CUI, Global robust dissipativity for integro-differential systems modeling neural networks with delays, Chaos, Solitons \& Fractals, 36 (2008), 469-478.

[13] Q. K. SONG, Z. J. ZHAO, Global dissipativity of neural networks with both variable and unbounded delays, Chaos, Solitons \& Fractals, 25 (2005), 393-401.

[14] T. JANKows KI, Delay integro-differential inequalities with initial time difference and applications, J. Math. Anal. Appl., 291 (2004), 605-624.

[15] X. R. MAO, M. RiEdLE, Mean square stability of stochastic Volterra integro-differential equations, Systems \& Control Letters, 55 (2006), 459-465. 
[16] M. Jovanović, S. JANKović, On perturbed nonlinear Itô type stochastic integrodifferential equations, J. Math. Anal. Appl., 269 (2002), 301-316.

[17] X. R. MAo, Stochastic Differential Equations and Applications, Horwood Publishing, 1997.

[18] S.-E. A. Mohammed, Stochastic Functional Differential Equations, Longman, New York, 1986.

[19] B. L. S. Prakasa RaO, Absolute stability of a stochastic integro-differential system, J. Math. Anal. Appl., 54 (1976), 666-673.

[20] K. Balachandran, S. KARThikeyan, Controllability of stochastic integrodifferential systems, Int. J. Control, 80 (2007), 486-491.

[21] A. Rathinasamy, K. Balachandran, Mean-square stability of Milstein method for linear hybrid stochastic delay integro-differential equations, Nonlinear Anal.: HS (2008), doi:10.1016/ j.nahs.2008.09.015.

[22] F. Y. WEI, K. WANG, The existence and uniqueness of the solution for stochastic functional differential equations with infinite delay, J. Math. Anal. Appl., 331 (2007), 516-531.

[23] R. A. Horn, C. R. Johnson, Topics in Matrix Analysis, vol. 2, Cambridge Univ. Press, England, 1991.

[24] Z. G. YANG, D. Y. XU, L. XIANG, Exponential p-stability of impulsive stochastic differential equations with delays, Phys. Lett. A, 359 (2006), 129-137.

[25] E. Beckenbach, R. Bellman, Inequalities, Springer-Verlag, New York, 1961.

[26] D. Y. XU, W. ZHU, S. J. LONG, Global exponential stability of impulsive integro-diffrential equation, Nonlinear Anal., 64 (2006), 2805-2816. 